\title{
Arber, Agnes, 2012 \\ The Natural Philosophy of Plant Form
}

Cambridge University Press, New York. 266 pp. £18.99, Paperback.

ISBN: 9781108045056 (www.cambridge.org/clc)

For most scholars in the West, studies on plant form (known as plant morphology) have been part of two main schools of thought. First, natural philosophy since Aristotle (pre-modernity tradition) and, second modern biology since the nineteen century (natural history and modern science). An attitude toward the organism as an integrated whole is common to find in the natural philosophy tradition. In contrast, modern biology treats the organism in a more analytical way, thereby treating the organism's form and function as a duality or as separate and independent entities. For long time, this dichotomy of form and function has been the source of an endless debate not only in the sciences and philosophy, but also in the arts, especially in architecture. A famous axiom in architecture states, "Form follows function". Among plant morphologists, there is, apparently, a consensus that form and function are two aspects of the same unity. However, the intimate nature of form or the dynamic of form is maintained under two interpretations (e.g. continuous and discrete morphology) for explanatory purposes. Agnes Arber (1879-1960) in her book The Natural Philosophy of Plant Form, first published in 1950, provides the basis for the continuous plant morphology and currently known as fuzzy Arberian morphology. Is the natural philosophy of plant form the new plant morphology? Was Arber right?

The book is divided into eleven chapters. The first chapter is an introduction to the meaning of plant morphology in the natural philosophy tradition (embraces ideas on the meaning and content of plant morphology). Chapters Two, Three and Four are a tour of the main schools in plant morphology from the Greeks, Aristotle and Theophrastus. Middle Ages, Albertus Magnus and Andrea Cesalpino. And later, from Joachim Jung ( $17^{\text {th }}$ century) to Goethe (1749-1832) and de Candolle (17781841). Chapter Five covers the concept of the organization type (Urpflanze). In Chapter Six, Arber introduces her ideas on the Partial-shoot theory of the leaf that she continues describing through Chapters Seven (includes an extension of previous chapter concerning the wholeshoot-hood in the leaf), Eight (includes more problems regarding the partial-shoot theory) and Nine (includes the topic of repetitive branching and the gestalt type). Chapter Ten describes the mechanism of plant morphology and Chapter Eleven its interpretation.

Arber found in the botany of the Aristotelian school a legacy of admirable description of plant fundamental features and the whole plant in terms of currently known areas of study such as morphology, physiology and biochemistry, reproduction and development, and life-histories. Theophrastus was describing organs -root and stem- with great details as shown by one of his records referring the structure of the palm stem: "the fibres [vascular bundles] do not run through the wood, nor do they run to a good length, nor are they all set symmetrically, but run in every direction" (p. 16-17). Arber describes the great contribution of Theophrastus on 
shoot morphology and the remarkable observation by him in distinguishing between monopodial and sympodial growth patterns. The Aristotelian idea that the roots of plants resemble the mouths of animals led Arber to picture the plant as an animal standing on its head. In this analogy, the plant root system resembles the neuron system of animals. This is a powerful metaphor in understanding the fundamental difference between animals and plants.

In her review of the relationship between parts in the flowering plants she distanced herself from the analytical approach and embraced the legacy of the Aristotelian natural philosophy. If form and function are two sides of the same coin, Arber found in this tradition the right element for the foundation of a deep morphology since the mid-twentieth century. In other words, Arberian plant morphology is now more of a source of integration and meaning than Classical morphology.

Arber was a distinguished British plant morphologist and a Fellow of the Royal Society. Her contribution, many years later, has shed light into the new field of evolutionary developmental biology, informally known as evo-devo. The Arberian fuzzy morphology has followers in different continents among plant morphologists. This school of morphology is still active and important contributions have been made thanks to the partial shoot theory of the leaf.

This book was not only important in the mid-twentieth century. It is also important in the twenty-first century for the new generation of plant morphologists looking for the legacy of natural philosophy into modern science. Arber's natural philosophy approach opened a new way to look at the plant form from a dynamic perspective that challenges the status quo of classical plant morphology. Because of that, Arber was right. Natural philosophy in the Aristotelian tradition brings the rationality to capture the fundamental essences of the organism. Contrary to modern science where the organism is interpreted narrowly in terms of mechanical explanations or to use the Aristotelian terms, material and efficient causes, the interpretation of plant morphology from the natural philosophy perspective includes also, the teleological aspects, final and formal causes, in terms of the Aristotelian tradition. As Arber referring to Kant says "mechanism without teleology is blind, while teleology without mechanism is empty" (p. 203). Currently, natural philosophy makes explicit the two sides of biology, mechanistic and teleological, and offers the pathway for a delayed reconciliation between both modes of thought. 